not only beautifully polished, sharp and symmetrical, but - as electron microscopy shows - were never actually used. So why were they made? His answer is that they were valued, as we say, for their own sake - in other words, for their ability to give us pleasure, which in turn rests on their value as fitness indicators of the men who made them.

Miller has many stimulating and unexpected things to say about these, and other, cultural matters. He's also good at jokes. His book will excite many people, and infuriate others - especially if they don't read it carefully. The Mating Mind is as far from naive biological determinism as it could be, without losing sight of our evolutionary heritage altogether. Reading this book enables a rich confusion of apparently unrelated details to fall into place - and isn't that what science is all about?

Margaret A. Boden is in the School of Cognitive and Computing Sciences, University of Sussex, Falmer, Brighton BN1 9QN, UK.

\section{Statistical detective}

\section{Statistics on the Table: The \\ History of Statistical \\ Concepts and Methods \\ by Stephen M. Stigler \\ Harvard University Press: 1999. 448 pp. \\ \$27.95, \$45}

\section{lan Hacking}

Stephen Stigler's previous book The History of Statistics: The Measurement of Uncertainty before 1900was a rare but splendid example of the history of a science written by one of its practitioners. It also conveyed a wry wit and insatiable curiosity that were not, however, allowed to distract from the main story. Stigler has also written occasional articles over the years, expressing his detective's delight in uncovering obscure but charming facts. In Statistics on the Table he has revised these pieces, which, although organized to develop a number of systematic lines of thought, are often so interesting individually that this could serve as a bedside book.

The title comes from a private letter by Karl Pearson, who wrote that, since you can draw any number of conclusions - sound and unsound - from statistical data, you should always put your data on the table and show how you analyse them before you state your inferences. Stigler shows how the desire to present data in compact, unbiased and accessible ways motivated the founding figures of his discipline. He also applies the motto to himself, setting out the data that bear on his own historical problems and telling how he came by them.

His focus is on figures who now seem minor; some you would never encounter

without Stigler as guide. Even when he turns to the famous, he directs us to the margins of their careers. Yet tucked away at the end of many of these pieces is a gently stated but powerful methodological moral for our times.

The essays are arranged in five sections. "Statistics and Social Sciences" begins with Pearson's relationships with the Cambridge economists, including the greatest: Marshall and Keynes. There are two chapters on Jevons and a very fine essay on Edgeworth, important enough in their day, but now almost unknown. After a bicentennial homage to Quetelet, we proceed to Galtonian notions. Stigler guides us through the traps of regression, with special reference to a bizarre series of tables published in 1933 by one Horace Secrist, who proved that American business was (necessarily, as shown by the mathematical theory of regression, and, in fact, as established by observation) regressing towards mediocrity. What seems like anecdote is, in fact, a veiled denunciation of the number-crunchers who employ vast software programs with no idea of the ideas they deploy, and no comprehension of the numbers that result.

As we progress through the book Stigler the detective becomes more and more in evidence. A bookseller's list piques his curiosity with a 1695 tract on The Art ofCuring Diseases by Mathematics, written by Sir Edward Eizat to denounce 'A.P.. This leads us to Edinburgh poet and physician Archibald Pitcairne (1652-1713), who opposed the unscientific medical practices of his day with a new theory of medicine based on mathematics. Any morals to draw here? This spat, by no means foolish in its details, is an example of what happens when mathematics tries to intrude into fields where there are already practitioners.

\title{
Aventis Prizes for Science Books 2000
}

The Elegant Universe by heretical theorist Brian Greene (Vintage, $\mathfrak{E 7 . 9 9 , ~ \$ 1 5 , ~ p b k ) ~ h a s ~ w o n ~ t h i s ~}$ year's Aventis Prizes General Prize — often called the scientific community's Booker Prize. The prizes were set up in 1988 by the Science Museum and COPUS, the Committee On the Public Understanding of Science, to encourage the writing, publishing and sale of popular science books for non-specialist readers. This year's general prize, worth $£ 10,000(\$ 15,000)$, attracted a record 117 entries. Other books on the shortlist are shown below. (See overleaf for coverage of the junior prize.)

The White Death: A History of Tuberculosis by Thomas Dormandy Hambledon/New York University Press, £25, \$29.95

\section{A Brief History of the Future: The}

In his section on naming, we are presented with Stigler's Law of Eponymy. The law states that (on the Principle of Humility) no law, theorem, principle or phenomenon is named after the person who discovered it. Its name is a joke: by self-reference, Stigler cannot have been the first to hit on Stigler's Law and, sure enough, he gives the credit to the sociologist of science Robert K. Merton. Humility triumphs, after all.

Various figures cross this section Gauss, Euler, Pearson - but "Who discovered Bayes's Theorem?" conveys the flavour. Richard Price published Bayes's most famous paper in 1765, four years after Bayes's death, but Stigler's Law says there must be a forgotten precursor. And yes, there is a mention of what sounds very much like Bayes's ideas in work published in 1749 by David Hartley, founder of associationist psychology. Hartley says of the Bayes-like result that it was communicated to him by an "ingenious friend". Who?

Stigler unearths a remarkable forgotten mathematician named Nicholas Saunderson. A good candidate, on data provided. But what would increase the credibility? In order to possess the requisite mathematics, including the binomial expansion, the friend would have to have read Abraham de Moivre, who set out matters clearly in a miscellany published in 1730. So who read de Moivre? Examine the list of subscribers to the first printing: Saunderson is there. From this and other reflections Stigler derives a list of suspects whom he will summon into the parlour his metaphor. After he has put all his data on the table, Stigler's 'Bayesian [ sic] calculation' gives odds of 3 to 1 on Saunderson. This is vintage Stigler.

Ian Hacking is in the Department of Philosophy, University of Toronto, 215 Huron Street, Toronto, Ontario M5S 1A1, Canada.
Origins of the Internet

by John Naughton

Weidenfeld \& Nicholson/Overlook, £18.99/\$27.95

Genome: The Autobiography of a Species in 23 Chapters

by Matt Ridley

Fourth Estate/HarperCollins, £9.99(pbk)/\$26 (hbk)

Time, Love, Memory: A Great Biologist and his Quest for the Origins of Behaviour

by Jonathan Weiner

Faber \& Faber/Knopf, £20/\$27.50

Children of Prometheus: The Accelerating Pace of Human Evolution by Christopher Wills

Allen Lane/Perseus, £20 (hbk)/\$15 (pbk) 